\title{
Modelling the Electrostrictive-force induced Cavitation Formation Process in Dielectric Liquids
}

DOI:

10.1109/ICHVE49031.2020.9279849

\section{Document Version}

Accepted author manuscript

Link to publication record in Manchester Research Explorer

\section{Citation for published version (APA):}

Liu, D., Liu, Q., Liu, B., \& Wang, Z. (2020). Modelling the Electrostrictive-force induced Cavitation Formation Process in Dielectric Liquids. In 2020 IEEE International Conference on High Voltage Engineering and Application https://doi.org/10.1109/ICHVE49031.2020.9279849

\section{Published in:}

2020 IEEE International Conference on High Voltage Engineering and Application

\section{Citing this paper}

Please note that where the full-text provided on Manchester Research Explorer is the Author Accepted Manuscript or Proof version this may differ from the final Published version. If citing, it is advised that you check and use the publisher's definitive version.

\section{General rights}

Copyright and moral rights for the publications made accessible in the Research Explorer are retained by the authors and/or other copyright owners and it is a condition of accessing publications that users recognise and abide by the legal requirements associated with these rights.

\section{Takedown policy}

If you believe that this document breaches copyright please refer to the University of Manchester's Takedown Procedures [http://man.ac.uk/04Y6Bo] or contact uml.scholarlycommunications@manchester.ac.uk providing relevant details, so we can investigate your claim.

\section{OPEN ACCESS}




\section{Modelling the Electrostrictive-force induced Cavitation Formation Process in Dielectric Liquids}

\author{
Donglin Liu \\ Department of Electrical and \\ Electronic Engineering \\ The University of Manchester \\ Manchester, United Kindom \\ donglin.liu-2@postgrad.manchester.ac.uk
}

\author{
Qiang Liu* \\ Department of Electrical and \\ Electronic Engineering \\ The University of Manchester \\ Manchester, United Kindom \\ qiang.liu@manchester.ac.uk
}

\author{
Zhongdong Wang \\ Department of Electrical and \\ Electronic Engineering \\ The University of Manchester \\ Manchester, United Kindom \\ zhongdong.wang@manchester.ac.uk
}

\author{
Boyan Liu \\ Department of Electrical and \\ Electronic Engineering \\ The University of Manchester \\ Manchester, United Kindom \\ boyan.liu@student.manchester.ac.uk
}

\begin{abstract}
Pre-breakdown phenomenon in dielectric liquids, also called streamer, has been widely investigated to understand the breakdown mechanism of dielectric liquids. The possibility of streamer initiation due to electrostrictive force induced cavitation formation under fast-rising voltage waveform is studied in this paper. The finite element method (FEM) based modelling is conducted by coupling Poisson equation and Navier-stoke equations in COMSOL Multiphysics. The pressure threshold of cavitation formation in cyclohexane and rapeseed oil is estimated to be $-6 \mathrm{MPa}$ and 9.31 MPa, respectively, which are 3-5 times smaller than that in deionized water (-30 MPa). This is mainly due to smaller surface tension coefficients of oils than deionized water. A detailed description on the dynamics of cavitation formation in deionized water is first presented and then compared with those in cyclohexane and rapeseed oil. Results showed that the electrostrictive pressure increases with the increasing applied voltage, which pushes local liquid towards the needle tip at tens of $\mathbf{m} / \mathbf{s}$ and leads to large negative pressure in the vicinity of needle tip. Cavitation appears in the area where local negative pressure reaches the threshold. The electrostrictive pressure in deionized water is around 100 and 60 times larger than that in cyclohexane and rapeseed oil, respectively, under the same conditions due to the larger relative permittivity of deionized water. Therefore, it is much harder to initiate cavitation in cyclohexane and rapeseed oil than in deionized water. In addition, the voltage magnitude thresholds for cavitation formation are comparable between cyclohexane and rapeseed oil under different voltage rising rates.
\end{abstract}

Keywords—dielectric liquids, cavitation, negative pressure, electrostrictive force

\section{INTRODUCTION}

Dielectric liquids, including polar and non-polar liquids, have been widely used in different high voltage equipment due to their desirable electrical and cooling properties. Polar dielectric liquids such as deionized water are suitable in pulsed applications and works well for short-term highenergy density storage due to high conductivity and relatively permittivity, respectively [1]. In comparison, nonpolar dielectric liquids such as mineral oil are preferred in power transformers ever since late $19^{\text {th }}$ century. Recent years, new alternatives, namely ester liquids, have gradually been used due to their better biodegradability, higher flash/fire points and superior moisture tolerance than mineral oil [2-4].
The pre-breakdown, also called streamers, and breakdown processes of dielectric liquids have been studied in the past decades [1, 5-9]. Streamer study can be categorized into initiation and propagation stages. However, compared to the knowledge of gas discharge, the mechanisms of streamer in dielectric liquid are less developed [6]. Apart from the traditional "bubble" theory and "direct ionization" theory [1], streamer initiation induced by cavitation formation under extremely fast-rising voltage has been proposed and studied in deionized water based on both experiments and simulations [9-12]. Electrons may gain enough energy inside cavitation, thus colliding with molecules on the surface of cavity and leading to electron avalanche [13]. The threshold of cavitation formation in deionized water is estimated to be $-30 \mathrm{MPa}$ [11]. Under electrostrictive force alone, liquid is pushed towards the needle tip, leading to a higher liquid density in the vicinity of needle tip and a lower liquid density a bit further away due to liquid inertia [11]. Negative pressure area is formed in the vicinity of needle tip, which stretches the local liquid and leads to the possibility of cavitation formation if the local negative pressure reaches a defined threshold [11]. However, few simulation or experimental study on the cavitation formation process in mineral oil or ester liquids has been conducted, which is worthy of investigation.

Since cyclohexane is generally regarded as a simplified alternative for mineral oil in some fundamental studies, in this paper, a comparison on the cavitation formation dynamics among deionized water, cyclohexane and rapeseed oil in a needle-plane geometry has been conducted in simulation. The controlling equations, including Poisson equation and Navier-Stokes equations, are solved by finite element method (FEM) in COMSOL Multiphysics. The detailed process of cavitation formation is described. The differences in the magnitude of electrostrictive force and liquid velocity among three liquids are presented. The minimum voltage magnitudes required for cavitation formation with different voltage rising rates are compared among the three liquids.

\section{Simulation SetuP}

The controlling equations of the simulation of cavitation formation are a coupling of Poisson equation (1), Navierstokes equations (2)-(3).

$$
\begin{gathered}
\varepsilon_{0} \varepsilon_{r} \nabla(-\nabla V)=c \\
\frac{\partial \rho_{l}}{\partial t}+\nabla \cdot\left(\rho_{l} \vec{v}\right)=0
\end{gathered}
$$




$$
\rho_{l}\left(\frac{\partial \vec{v}}{\partial t}+(\vec{v} \cdot \nabla) \vec{v}\right)=-\nabla p+\vec{F}
$$

Where $V$ is voltage potential in $\mathrm{V}, \varepsilon_{0}$ is permittivity of vacuum, $\varepsilon_{r}$ is the relative permittivity and equals 81,2 and 3.1 for deionized water, cyclohexane and rapeseed oil, respectively, $c$ is the charge density which is assumed to be zero for simplification in this paper without considering charge generation, $\rho_{l}$ is the liquid density, $\vec{v}$ is the liquid velocity, $\vec{F}$ is volumetric force, $p$ is the thermodynamic pressure of dielectric liquid.

The volumetric force $\vec{F}$ acting on the dielectric liquid can be expressed by Helmholtz equation [14, 15] as equation (4), where the three components represent Coulomb force, force related with local inhomogeneity and electrostrictive force. According to Clausius-Mosotti formula [16], $\left(\partial \varepsilon_{r} / \partial \rho_{l}\right) \cdot \rho_{l}$ in polar and non-polar liquids can be simplified as equation (5) and (6), respectively.

$$
\begin{gathered}
\vec{F}=\vec{E} c-\frac{\varepsilon_{0}}{2}|\vec{E}|^{2} \nabla \varepsilon_{r}+\frac{\varepsilon_{0}}{2} \nabla\left(|\vec{E}|^{2} \frac{\partial \varepsilon_{r}}{\partial \rho_{l}} \rho_{l}\right) \\
\frac{\partial \varepsilon_{r}}{\partial \rho_{l}} \rho_{l}=\alpha \varepsilon_{r} \\
\frac{\partial \varepsilon_{r}}{\partial \rho_{l}} \rho_{l}=\frac{\left(\varepsilon_{r}-1\right)\left(\varepsilon_{r}+1\right)}{3}
\end{gathered}
$$

Where $\vec{E}$ is local electric field, $\alpha \leq 1.5$ is the empirical factor for most of the studied polar dielectric liquids including deionized water $[11,17] . \alpha=1.5$ is used in this paper.

The relationship between thermodynamic pressure and liquid density is shown by equation (7) for deionized water $[9,11]$ and (8) for cyclohexane [18] and rapeseed oil [19] according to equation of state. A summary of the values of $\rho_{0}, B, C$ and $\gamma$ of three liquids is shown in TABLE I.

$$
\begin{gathered}
p=\left(p_{0}+B\right)\left(\frac{\rho_{l}}{\rho_{0}}\right)^{\gamma}-B \\
\rho_{l}=\frac{\rho_{0}}{1+\operatorname{Cln}\left(\frac{B+p_{0}}{B+p}\right)}
\end{gathered}
$$

Where $p_{0}$ is atmosphere pressure $(0.1 M P a) . \rho_{0}$ is the liquid density under atmosphere pressure and room temperature. $B$, $C$ and $\gamma$ are constant parameters

TABLE I. SUMMARY OF THE PARAMETERS USED IN EQUATION OF STATE OF DEIONIZED WATER, CYCLOHEXANE AND RAPESEED OIL

\begin{tabular}{|c|c|c|c|}
\hline \multirow{2}{*}{ Parameters } & \multicolumn{3}{|c|}{ References } \\
\cline { 2 - 4 } & $\begin{array}{c}\text { Deionized Water } \\
{[\mathbf{9 , 1 1}]}\end{array}$ & $\begin{array}{c}\text { Cyclohexane } \\
{[\mathbf{1 8}]}\end{array}$ & Rapeseed oil [19] \\
\hline$\rho_{0}\left(\mathrm{kgm}^{-3}\right)$ & 1000 & 774.1 & 907.3 \\
\hline$B(\mathrm{MPa})$ & 307 & 40.96 & 380 \\
\hline$C$ & --- & 0.05382 & 0.052 \\
\hline$\gamma$ & 7.5 & --- & --- \\
\hline
\end{tabular}

The electrode geometry used in this paper is a needleplane geometry as is shown in Fig. 1 with needle tip radius of $40 \mu \mathrm{m}$ and gap distance of $50 \mathrm{~mm}$. The diameter of plane electrode is set to be large enough $(300 \mathrm{~mm})$ to remove its effects on electric field distribution. The applied voltage is set to be ramp voltage which keeps increasing with rising rate equal to $50 \mathrm{kV} / \mathrm{ns}$ and $90 \mathrm{kV} / \mathrm{ns}$ respectively. B1, B2 and B3 are the boundaries of the simulation domain which are large enough. In COMSOL Multiphysics, the simulation is built in 2D-axisymmetric model so that only half of the geometry divided by symmetric axis (z-axis) will be shown in the results.

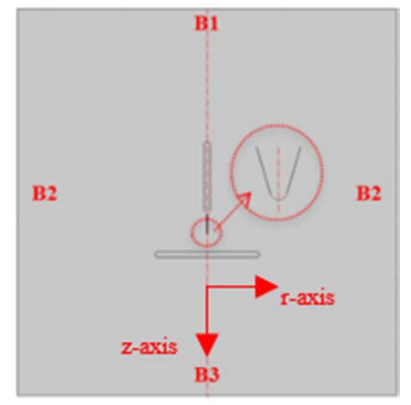

Fig. 1. Schematic diagram of needle-plane geometry with boundary numbering plotted

\section{SIMULATION RESULTS}

\section{A. Estimation on the threshold of cavitation formation}

Generally speaking, liquid may form micro ruptures, also known as cavitation, when being stretched [10]. The possibility of cavitation formation in liquids is expressed by total pressure $p_{\text {total }}$ of liquid under certain volumetric force. Combining (3) and (4) when only considering electrostrictive force, $p_{\text {total }}$ is expressed by (9). The second term on the right side of equation (9) is called electrostrictive pressure. When $p_{\text {total }}$ reaches a threshold of critical pressure $p_{c}$, cavitation forms. $p_{c}$ is expressed by (10) according to nucleation theory [20]. However, in experiments $p_{c}$ in deionized water is tested to range between $-50 \mathrm{MPa}$ and $-6 \mathrm{MPa}$ while $p_{c}$ is calculated to be about -184 to $150 \mathrm{MPa}$ based on (10), which is an enormous overestimation $[11,21]$. The reason may be that $p_{c}$ is sensitive with the degree of purity of liquid and the presence of dissolved gas and dust particles [11].

In simulation [11], $p_{c}$ in deionized water was assumed to be $-30 M P a$. Since $p_{c}$ should be mainly dependent on the surface tension coefficient $\sigma$ of liquid other than other parameters according to (10) and due to lack of experimental results on $p_{c}$ for other liquids, in this paper, we simply assume that the differences in $p_{c}$ of different dielectric liquids are also dependent on $\sigma$. Comparing the surface tension coefficient of cyclohexane and rapeseed oil which are $0.024 \mathrm{~N} / \mathrm{m}^{3}$ [22] and $0.033 \mathrm{~N} / \mathrm{m}^{3}$ [23] with deionized water $0.072 \mathrm{~N} / \mathrm{m}^{3}$ [24], here the threshold for cavitation formation in cyclohexane and rapeseed oil is estimated to be $-6 \mathrm{MPa}$ and $-9.31 \mathrm{MPa}$.

$$
\begin{gathered}
p_{\text {total }}=p-\frac{\varepsilon_{0}}{2} \frac{\partial \varepsilon_{r}}{\partial \rho_{l}} \rho_{l}|\vec{E}|^{2} \\
p_{c}=p_{\text {sat }}-\sqrt{\left(\frac{16 \pi \sigma^{3}}{3 k T \ln (N B / J)}\right)}
\end{gathered}
$$

Where $p_{s a t}$ is the vapour pressure of liquid, $\sigma$ is the surface tension coefficient, $k$ is Boltzmann constant, $N$ is the density of molecules and is $10^{20} \sim 10^{28} \mathrm{~m}^{-3}$ for water, cyclohexane and rapeseed oil, $B$ is the kinetic coefficient and is $10^{11} \sim 10^{15} \mathrm{~s}[11,25], \mathrm{J}$ is the nucleation rate equal to the density of vapour bubbles of a critical size appearing per 1 second and generally ranges from $10^{18} \sim 10^{22}, T$ is temperature in $\mathrm{K}$.

\section{B. Description of cavitation dynamics in deionized water}

The description of electrostrictive pressure in deionized water under voltage rising rate equal to $50 \mathrm{kV} / \mathrm{ns}$ is shown in Fig. 2. The increase of electrostrictive force is dramatic with time due to its relationship with local electric field as is shown in the second term on the righthand side of equation 
(9). The value of electrostrictive pressure is negative which contributes to the generation of cavitation. The values of total pressure shown in Fig. 3 are similar with those of the electrostrictive pressure because the thermodynamic pressure is small and cannot change too much during this short time period (several nanoseconds). The total pressure is lower than -30 MPa from needle tip into the deionized water bulk which means cavitation can probably form in this area.

In $2 \mathrm{D}$ plot in Fig. 4, the direction of red arrows show the directions of local liquid movements while the sizes of arrows indicate the relative relationship of the magnitudes of local velocity in logarithm scale. Under the drift of electrostrictive force, the liquid is pushed towards the needle tip at tens of $\mathrm{m} / \mathrm{s}$. Besides, with the increase of time, more liquids are pushed by electrostrictive force with higher speed due to higher applied voltage.

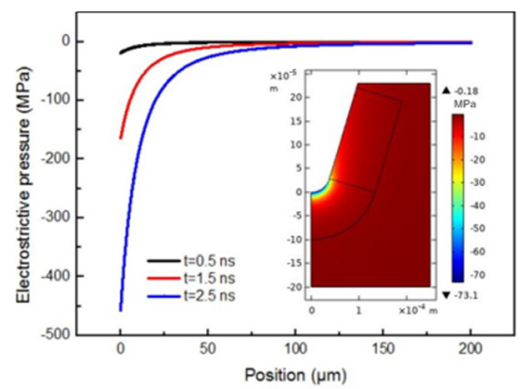

Fig. 2. Distribution of electrostrictive pressure along z-axis at different time moment and in $2 \mathrm{D}$ plot at $\mathrm{t}=1 \mathrm{~ns}$ in deionized water. voltage rising rate equals $50 \mathrm{kV} / \mathrm{ns}$

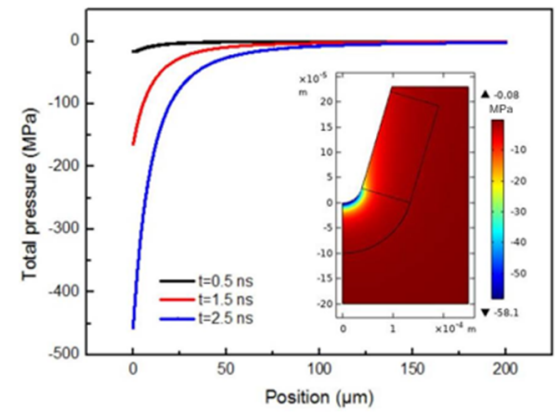

Fig. 3. Distribution of total pressure along z-axis at different time moment and in $2 \mathrm{D}$ plot at $\mathrm{t}=1 \mathrm{~ns}$ in deionized water. Voltage rising rate equals 50 $\mathrm{kV} / \mathrm{ns}$

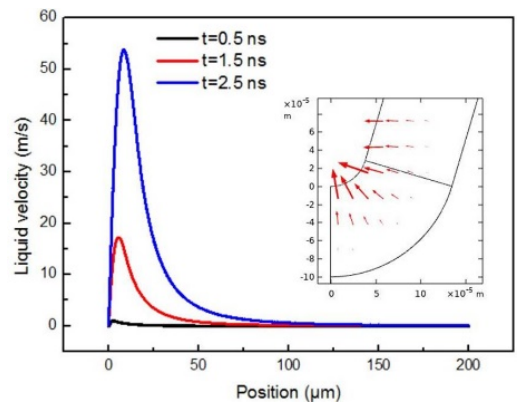

Fig. 4. Distribution of liquid velocity along z-axis at different time moment and in $2 \mathrm{D}$ plot at $\mathrm{t}=1 \mathrm{~ns}$ in deionized water. The length of arrows in the $2 \mathrm{D}$ plot represents the magnitude of liquid velocity in logarithm scale. Voltage rising rate equals $50 \mathrm{kV} / \mathrm{ns}$

\section{Comparison on the cavitation dynamics among different dielectric liquids}

The distributions of absolute values of electrostrictive pressure of three kinds of dielectric liquids along z-axis at
$2.5 \mathrm{~ns}$ when voltage rising rate equals $50 \mathrm{kV} / \mathrm{ns}$ are shown in Fig. 5. Note that all of the electrostrictive pressure are negative value but only magnitudes are compared here. Because the relative permittivity of deionized water is around 40 times larger than cyclohexane and rapeseed oil and the different simplified forms of $\left(\partial \varepsilon_{r} / \partial \rho_{l}\right) \cdot \rho_{l}$ based on Clausius-Mosotti formula, the electrostrictive force in deionized water is around 125 times and 50 times larger than that in cyclohexane and rapeseed oil, respectively. Correspondingly, the liquid velocity in deionized water is $\sim 75$ times larger than both cyclohexane and rapeseed oil as is shown in Fig. 6. The maximum liquid velocity of rapeseed oil is similar with that of cyclohexane. However, more rapeseed oil can be pushed towards the needle tip than cyclohexane.

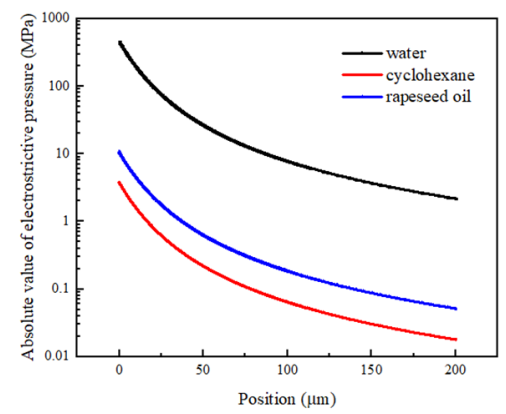

Fig. 5. Comparison of the distribution of electrostrictive pressure along $\mathrm{z}$ axis among deionized water, cyclohexane and rapeseed oil at $2.5 \mathrm{~ns}$. Voltage rising rate equals $50 \mathrm{kV} / \mathrm{ns}$

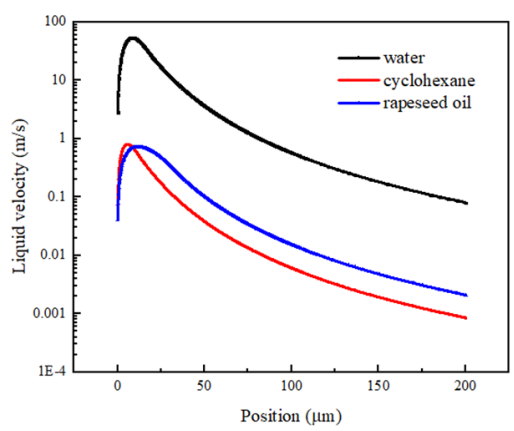

Fig. 6. Comparison of the distribution of liquid velocity along z-axis among deionized water, cyclohexane and rapeseed oil at $2.5 \mathrm{~ns}$

\section{Comparison on the voltage magnitude threshold of cavitation formation}

Since the lowest pressure always happens at the needle tip, it is reasonable to regard the voltage under which $p_{\text {total }}$ at needle tip just reaches $p_{c}$ as the voltage threshold of cavitation formation under electrostrictive force alone. The time-dependent total pressure at needle tip in three liquids under voltage rising rate equal to $50 \mathrm{kV} / \mathrm{ns}$ is shown in Fig. 7 (a). With the increase of time, the total pressure of deionized water decreases so fast that it quickly reaches the threshold while that of cyclohexane and rapeseed oil gradually drops but can also lead to cavitation. Based on the estimated threshold of cavitation formation among three liquids, the voltage magnitude thresholds for deionized water, cyclohexane and rapeseed oil are around $35 \mathrm{kV}, 215 \mathrm{kV}$ and $330 \mathrm{kV}$, respectively. When increasing the voltage rising rate to $90 \mathrm{kV} / \mathrm{ns}$, the threshold of cavitation formation are around $33.6 \mathrm{kV}, 189 \mathrm{kV}$ and $171 \mathrm{kV}$ for deionized water, cyclohexane and rapeseed oil, respectively as is shown in Fig. 7(b). Therefore, it is easy to conclude that cavitation is easier to form in deionized water than in other two liquids due to 
the high relative permittivity of deionized water. Besides, because slower voltage rising rate gives liquids more time to move towards the needle tip and respond to the electrostrictive force, much higher voltage magnitudes are required to form cavitation than under higher voltage rising rate.

This paper only involved electrostrictive force without consideration of charge generation. However, it should be noted that streamer is able to happen under these high voltage magnitudes for cyclohexane and rapeseed oil so that charge are already generated. Therefore, besides electrostrictive force, coulomb force shown as the first term on the right side of (4) should also be considered to study its effects on cavitation formation during streamer initiation stage.

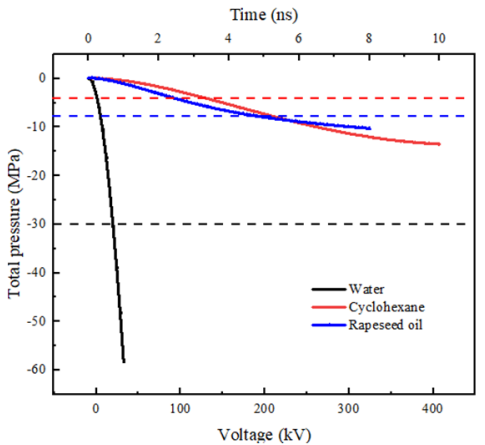

(a) $50 \mathrm{kV} / \mathrm{ns}$

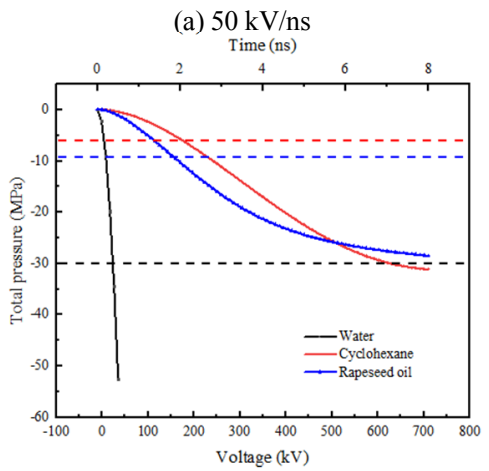

(b) $90 \mathrm{kV} / \mathrm{ns}$

Fig. 7. Comparison of the voltage threshold for cavitation formation among deionized water, cyclohexane and rapeseed oil at different voltage rising rate (a) $50 \mathrm{kV} / \mathrm{ns}$ and (b) $90 \mathrm{kV} / \mathrm{ns}$

\section{CONCLUSION}

This paper conducted simulation studies on the possibility of cavitation formation in deionized water, cyclohexane and rapeseed oil induced by electrostrictive force alone. The pressure thresholds of cavitation formation in cyclohexane and rapeseed oil are estimated to be $-6 \mathrm{MPa}$ and -9.31 $\mathrm{MPa}$ respectively, which are smaller than deionized water due to smaller surface tension. Simulations find that it is much easier to form cavitation in deionized water than in cyclohexane and rapeseed oil because larger relative permittivity of deionized water leads to larger electrostrictive force. Slower voltage rising rate requires higher voltage magnitude to initiate cavitation in all three liquids.

\section{REFERENCES}

[1] J. F. Kolb, R. P. Joshi, S. Xiao, and K. H. Schoenbach, "Streamers in water and other dielectric liquids," Journal of Physics D: Applied Physics, vol. 41, no. 23, p. 234007, 2008/11/20 2008.
[2] T. V. Oommen, "Vegetable oils for liquid-filled transformers," IEEE Electrical Insulation Magazine, vol. 18, no. 1, pp. 6-11, 2002.

[3] L. Lewand, "Laboratory evaluation of several synthetic and agricultural-based dielectric liquids," in Doble Int. Client Conf E, 2001, vol. 5, p. 2001.

[4] S. Tenbohlen and M. Koch, "Aging performance and moisture solubility of vegetable oils for power transformers," IEEE transactions on power delivery, vol. 25, no. 2, pp. 825-830, 2010.

[5] O. Lesaint and L. Costeanu, "Positive streamer inception in cyclohexane: Experimental characterization and cavitation mechanisms," IEEE Transactions on Dielectrics and Electrical Insulation, vol. 25, no. 5, pp. 1949-1957, 2018.

[6] O. Lesaint, "Prebreakdown phenomena in liquids: propagation 'modes' and basic physical properties," Journal of Physics D: Applied Physics, vol. 49, no. 14, p. 144001, 2016.

[7] Q. Liu and Z.D. Wang, "Streamer characteristic and breakdown in synthetic and natural ester transformer liquids under standard lightning impulse voltage," IEEE Transactions on Dielectrics and Electrical Insulation, vol. 18, no. 1, pp. 285-294, 2011.

[8] I. L. Marinov, O. Guaitella, A. Rousseau, and S. M. Starikovskaia, "Successive Nanosecond Discharges in Water," IEEE Transactions on Plasma Science, vol. 39, no. 11, pp. 2672-2673, 2011.

[9] P. Mikhail, S. Yohan, N. S. Mikhail, F. Alexander, and D. Danil, "Initiation stage of nanosecond breakdown in liquid," Journal of Physics D: Applied Physics, vol. 47, no. 2, p. 025502, 2014.

[10] M. N. Shneider, M. Pekker, and A. Fridman, "Theoretical study of the initial stage of sub-nanosecond pulsed breakdown in liquid dielectrics," IEEE Transactions on Dielectrics and Electrical Insulation, vol. 19, no. 5, pp. 1579-1582, 2012.

[11] M. N. Shneider and M. Pekker, "Dielectric fluid in inhomogeneous pulsed electric field," Physical Review E, vol. 87, no. 4, p. 043004, 04/09/ 2013

[12] M. N. Shneider and M. Pekker, "Liquid dielectrics in an inhomogeneous pulsed electric field," Liquid Dielectrics in an Inhomogeneous Pulsed Electric Field, by Shneider, MN; Pekker, M.. ISBN: 978-0-7503-1245-5. IOP ebooks. Bristol, UK: IOP Publishing, 2016, 2016.

[13] D. Dobrynin, Y. Seepersad, M. Pekker, M. Shneider, G. Friedman, and A. Fridman, "Non-equilibrium nanosecond-pulsed plasma generation in the liquid phase (water, PDMS) without bubbles: fast imaging, spectroscopy and leader-type model," Journal of Physics D: Applied Physics, vol. 46, no. 10, p. 105201, 2013/02/08 2013.

[14] L. D. Landau and E. M. Lifshitz, Electrodynamics of Continuous Media (2nd ed). Oxford: Pergamon Press, 1984.

[15] I. E. Tamm, Fundamentals of The Theory of Electricity. Moscow: Mir Publ, 1979.

[16] W. K. H. Panofsky and M. Phillips, Classical Electricity and Magnetism. Addison-Wesley Pub. Co., 1962.

[17] V. Y. Ushakov, V. Klimkin, and S. Korobeynikov, "Breakdown in liquids at impulse voltage," NTL, Russia, Tomsk, 2005.

[18] J. A. Amorim, O. Chiavone-Filho, M. L. Paredes, and K. Rajagopal, "Modeling high-pressure densities at wide temperature range with volume scaling: Cyclohexane+ n-hexadecane mixtures," Fluid Phase Equilibria, vol. 259, no. 1, pp. 89-98, 2007.

[19] A. J. Rostocki, D. B. Tefelski, and S. Ptasznik, "Compressibility studies of some vegetable oils up to $1 \mathrm{GPa}$," High Pressure Research, vol. 29, no. 4, pp. 721-725, 2009/12/01 2009.

[20] V. P. Skripov, R. Kondor, and D. Slutzkin, Metastable liquids. Wiley New York, 1974.

[21] V. E. Vinogradov, "Depression of the cavitation centers in water under pulsed tension conditions," Technical Physics Letters, vol. 35, no. 1, pp. 54-56, 2009/01/01 2009.

[22] A. Villares, B. Giner, H. Artigas, C. Lafuente, and F. Royo, "Study of the surface tensions of cyclohexane or methylcyclohexane with some cyclic ethers," Journal of solution chemistry, vol. 34, no. 2, pp. 185198,2005

[23] E. A. Melo-Espinosa et al., "Surface Tension Prediction of Vegetable Oils Using Artificial Neural Networks and Multiple Linear Regression," Energy Procedia, vol. 57, pp. 886-895, 2014/01/01/ 2014.

[24] G. Vazquez, E. Alvarez, and J. M. Navaza, "Surface tension of alcohol water+ water from 20 to 50. degree. C," Journal of chemical and engineering data, vol. 40, no. 3, pp. 611-614, 1995.

[25] Y. Viisanen, R. Strey, and H. Reiss, "Homogeneous nucleation rates for water," The Journal of Chemical Physics, vol. 99, no. 6, pp. 46804692, 1993/09/15 1993. 